\title{
Tipicidad y fragmentariedad criminal en la España moderna*
}

\section{Criminal types and criminal fragmentation in Modern Spain}

\author{
Enrique ÁLVAREZ CORA \\ Catedrático acreditado de Historia del Derecho \\ Universidad de Murcia \\ eacora@um.es
}

These wonderful things

Were planted on the surface of a round mind that was to become our present time.

The mark of things belongs to someone

But if that somebody was wise Then the whole of things might be different From what it was thought to be in the beginning, before an angel bandaged the field glasses. John Ashbery, The Tennis Court Oath

Recibido: 1 de febrero de 2013

Aceptado: 8 de abril de 2013

\section{RESUMEN}

El trabajo analiza las características de la tipicidad delictiva en el Derecho penal de la Edad Moderna: su legalidad, su descriptividad y su fragmentariedad. En este sentido se considera la función que cumple, en la relación entre tipos delictivos y tipos penales, el orden jurídico interno del ius proprium - atendiendo tanto a la ley cuanto al arbitrio judicial—, así como la supletoriedad del ius commune. De nuevo a propósito de la tipicidad descriptiva y fragmentada, se estudia la qualitas delicti como factor modificativo de la obligación criminal.

PALABRAS CLAVE: Delito, pena, tipicidad, circunstancias modificativas de la responsabilidad criminal, Edad Moderna.

\begin{abstract}
This research analyzes the features of the criminal legal description in Criminal Law of Modern Age: its legality, its descriptive and fragmentary natures. In this sense it is considered the function that it obeys (in relation between criminal types and penal types) the internal legal order of ius propium (attending to the statute whatever the judicial discretion), and also the supplementary of ius commune.
\end{abstract}

\footnotetext{
* Este trabajo pertenece al Proyecto de Investigación titulado "Delincuencia y represión jurídica en España: teoría y praxis histórica de las figuras delictivas II", financiado por el Ministerio de Economía y Competitividad, ref. DER2012-31098.
} 
Again, in relation to the descriptive and fragmented legal description, the qualitas delicti it's studied as a modified cause of the criminal obligation.

KEYWORDS: Crime, punishment, legal description, modified circumstances of the criminal responsibility, Modern Age.

\section{RÉSUMÉ}

Cette recherche analyse les caractéristiques de la typicité des délits en droit pénal à l'âge moderne: sa légalité, son caractère descriptif et sa fragmentation. En ce sens, nous considérons le rôle accompli par l'ordre juridique interne du jus proprium - visant la loi aussi bien que le pouvoir discrétionnaire de la cour -, dans la relation entre les types criminelles et pénales, ainsi que l'utilisation supplémentaire du jus commune. Encore une fois par rapport à la description juridique descriptive et fragmentée, la qualitas delicti est étudiée comme facteur modifiant de la responsabilité pénale.

MOTS CLÉ: Crime, peine, typicité, circonstances modificatives de la responsabilité pénale, Âge Moderne.

\section{ZUSAMMENFASSUNG}

Dieser Beitrag analysiert die typisierenden Beschreibungen der Delikte im Strafrecht der Neuzeit: seine Gesetzmäßigkeit, seine beschreibende und fragmentarische Natur. In diesem Sinne gilt als seine Funktion, dass es der internen Rechtsordnung des ius proprium (in Beziehung zwischen verschiedenen Strafarten und Deliktstypen) gehorcht (dem Statut folgende, wie auch immer das gerichtliche Urteil ausfallen möge) und ebenso dem ergänzenden ius commune. Wiederum in Relation zu seinen beschreibenden und fragmentarischen rechtlichen Begriffsdefinitionen untersucht der Artikel die Deliktsqualitäten als eine modifizierte Ursache der strafrechtlichen Schuld.

SCHLÜSSELWÖRTER: Delikt, Strafe, Typizität, Modifizierte Umstände der strafrechtlichen Verantwortlichkeit, Neuzeit.

La catalogación de los tipos delictivos en la normativa de la Edad Moderna ${ }^{1}$, que es a su vez una catalogación de arrastre bajomedieval, invoca una concepción persistente del tiempo ${ }^{2}$ que repercute negativamente en la viabilidad de una red dogmática densa y actual de contenido sistémico que sería la que podría permitir, precisamente, la propagación de una tipicidad concentrada y unitaria. Los tipos funcionan en la medida en la que una estructura semántica global fija — no móvil, en el tiempo - los cubre, porque no en vano el calificativo específico los determina, sobre todo desde el punto de vista de la comparación entre sí. Sólo en cuanto la globalidad

\footnotetext{
${ }^{1}$ Para no incurrir en repetidas autocitas, vid. como pilar de estas reflexiones la aparente mera catalogación desarrollada en La tipicidad de los delitos en la España moderna, Madrid, 2012; estas páginas son una autolectura y hacen explícitas algunas de las ideas que en aquellas otras van implícitas.

${ }^{2}$ Sin discriminación por mor de criterios ideológicos pactistas o corporativistas, la innovación en la persistencia, es decir, el respeto a lo pretérito y la fundamentación política de la necesidad de normas advenidas en el presente, son comunes a las coronas de Castilla y Aragón, dentro de una proximidad sustancial de sistemas normativos.
} 
sistémica pare tipos, hay tipos cerrados y recíprocamente ajustados: la especificidad de los tipos alumbra entonces como representaciones semánticas que sobresalen y toman relieve en sus diferencias respecto de un género (es lo que sucede en la codificación decimonónica). Pero también hay tipos rotos, medionacidos, monstruosos, sajados, deshilachados, al compás de un paraguas estructural descompuesto, torreinclinado, no cuajado. El criterio de persistencia temporal del Derecho clásico dificulta precisamente una previa concepción sistémica y ofrece un aspecto de nave en construcción. No hay un eje estructurador ex novo, sino — en el mejor de los casos-sobrevenido o matizado, ex tunc. Esto permite la reduplicación, la corrección y aun la contradicción de tipos - las variaciones del mismo tipo- pero también su apuntalamiento e impostación. Mas la impostación cohabita con el solapamiento.

Cuando Tomás y Valiente reflexiona sobre el tipo delictivo fragmentado y descriptivo $^{3}$ como característico del Derecho clásico, se está refiriendo a un despedazamiento del tipo en virtud de la pluralidad de los cauces formales de normación. Cuando recompones un tipo delictivo en virtud del análisis de distintos preceptos, con distintos o similares vehículos formales de manifestación, la operación puede desembocar en contradicciones internas del tipo, dentro de un diseño normativo imperfecto, o bien en el encaje perfecto de las características concretas del tipo, dentro de un diseño normativo perfecto. Curiosamente la recomposición de los tipos delictivos a partir de su fragmentación normativa no da lugar a antinomias frecuentes en las recopilaciones modernas: la lectura de lo pretérito es seria, la cascada no está descontrolada, o los libros que agrupan partes o el todo de la fragmentación no son improvisados ni la fragmentación implica caos, aunque sí acaso asistematicidad o protosistematicidad. Porque lo relevante a la postre es el acto del despedazamiento mismo, que en realidad no es un acto a priori, sino la deriva de un habla normativa que reajusta el criterio de persistencia temporal, obviamente sin cuestionarlo: la actualización es propiamente una reactualización o sustitución, y no una abrogación, y el acto mismo posible y excepcional de abrogación no implica una mutación del criterio de persistencia temporal presumido en la manifestación de las normas, sino la advertencia de un cambio concreto necesario (un apunte o advenimiento normativo con razón política), cuando no de un desuso que por su propia naturaleza reafirma un criterio de persistencia temporal (esta vez desaparecido).

El criterio de persistencia temporal de las normas tiene sin embargo distintos efectos según la forma de su expresión obedezca ora a meras pautas acumulativas ora a una reformulación, por ejemplo en libros que revis(it)an — vuelta a las recopilaciones- Cuando el nuevo libro moderno acumula libros o cuadernos medievales o modernos - así por regla general en las recopilaciones navarras y de la corona de Aragón- el encaje de los tipos penales de los libros incorporados resulta más pro-

\footnotetext{
${ }^{3}$ Francisco Tomás y Valiente, El Derecho penal de la Monarquía absoluta (siglos XVI-XVII-XVIII), Madrid, 1969, pp. 203-210.
} 
blemático y deslavazado que cuando el nuevo libro sustituye a libros - cuyo contenido puede acumularse o seleccionarse- como nueva recopilación - así en el Derecho castellano - y se propone como lectura resucitada e innovadora de la tradición. Pero ni en uno ni en otro caso se consigue un conjunto sistémico para la lectura de los tipos delictivos. En el primer caso, porque la reagrupación no muta la aparición fragmentada otrora de los tipos delictivos. En el segundo caso, porque la selección de los contenidos materiales no anula la formulación de los tipos que pudo haber tenido lugar en las fuentes que restan apartadas, como una película desprendida; de hecho también los nuevos tipos hurtan su definición - son descriptivos, una vez más, en efecto- porque de alguna manera prolongan aún la indefinición tradicional, o siguen el tradicional predominio de una descripción fragmentada - y en ella se basany por lo tanto tampoco empujan a una conjunción sistémica global que pueda funcionar como un a priori: gustan de una naturaleza sobrevenida que a su vez y paradójicamente se antoja original, o sea, brotan en el tiempo eviterno, conjugación de un futuro perfecto de subjuntivo. Se trata de la idea clásica — pero ya visigoda - de una renovación en la tradición. Dicho de otra manera, la recopilación de lo viejo es una precipitación de tipos viejos fragmentados, y la recopilación de lo viejo y de lo nuevo es una recopilación de tipos viejos fragmentados y de tipos nuevos tan fragmentados como los viejos, sólo nuevos en cuanto mutación o agregación a lo viejo. Por otra parte es suficientemente llamativo el mero hecho de que la recopilación sobrevenida no sólo respete la descripción fragmentada de tipos delictivos, sino que incluya pocas novedades en la fragmentación. Por supuesto, la circunstancia de que la recopilación se proponga como nueva ley o como vieja ley contra la ignorantia iuris regia no afecta a lo que aquí se dice, que tiene que ver con la técnica de descripción del tipo delictivo en concreto.

Conviene tener en cuenta que cuando reflexionas acerca de la fragmentación de los tipos delictivos, precisamente es por mor de la función descriptiva del tipo penal que asume la norma. Los tipos delictivos sólo son descritos, o se definen describiéndose, una de dos. En tanto la definición tiene una vocación de clausura, la descripción es por naturaleza abierta. El ejemplo más claro está en las Partidas, que quizá es el cuerpo legal que define con más frecuencia los delitos (sin duda por su carácter enciclopédico, como es sabido, y su virtud de espejo de la cultura grecolatina y el ius commune), pero los define describiéndolos, acumulando la descripción de una serie de actos subsumidos en el tipo delictivo: así en el crimen de lesa majestad divina o humana, la falsedad, el adulterio, la bigamia, el incesto, el robo, el hurto y el daño ${ }^{4}$. No es, sin embargo, la única fuente donde cabe localizar definiciones por descripción. En Castilla, antes, el Fuero Real define por descripción la injuria, y después, la Nueva Recopilación incorpora la definición por descripción del crimen de lesa majestad, la

\footnotetext{
${ }^{4}$ Vid. mi trabajo titulado "El Derecho penal de Alfonso X", Initium. Revista Catalana d'Història del Dret, 16, 2011, pp. 283-296.
} 
blasfemia, el duelo, el incesto, la vagancia y la mendicidad, o los juegos prohibidos. En Navarra, no hay definición por descripción de tipos delictivos, sino mera descripción de actos penalizados. En Aragón, se define/describe el maleficio contra la paz o tregua del rey, y los delitos atroces. En Cataluña, de nuevo el mal contra la paz o tregua del rey. Y en Valencia, el crimen de lesa majestad y el adulterio. Si se tiene en cuenta la multiplicidad de tipos delictivos, las definiciones por descripción (o las descripciones al servicio de una supuesta definición diríamos plástica) son excepcionales, y por regla general coincidentes en delitos gravísimos, con protección de la república. En Castilla, donde la frecuencia de definición descriptiva es mayor, aun reducida, tiene mucho sentido que las leyes modernas, incluidas en la Nueva Recopilación, procuren también la definición descriptiva precisamente de las conductas novedosamente penalizadas: así los delitos de germanía, típicos de la legislación de Felipe II, se definen efectivamente, para mayor seguridad jurídica (por su complejidad y maraña), a través de la descripción de las conductas penalizadas que subsumen.

La fragmentación es un a posteriori de la descripción, expresa o tácitamente, es decir, o bien la descripción nacida en una norma continúa desarrollándose en otras normas, coetáneas o posteriores, expresamente, o bien las normas posteriores simplemente se acomodan de forma tácita a partir de la descripción preexistente. Pero, incluso cuando la norma moderna responde a un problema nuevo, la técnica sigue siendo la misma: la descripción de los nuevos supuestos, que o bien desarrollan con originalidad las vicisitudes de la política criminal actual como nuevos frentes de problemas pretéritos, o bien establecen una nueva línea de represión describiendo sin definir, o definiendo mediante descripciones, de raíz.

Como se ve, una cosa es que el tipo delictivo se defina describiéndose, lo cual resulta excepcional, y otra cosa es la proliferación de los tipos delictivos por descripción. Una cosa es la definición descriptiva de un tipo delictivo, y otra cosa es la profusión de descripciones como tipos delictivos. Pero hay homeostasis entre las dos cosas. Por lo tanto, quizá podría entenderse simultáneamente, a la inversa, que todos los libros, acumulativamente, en función del criterio de persistencia temporal, proceden a describir para proseguir - concretamente, en el interés propio de cada norma, en su finalidad - con la definición descriptiva que otras normas - también con su propio interés o finalidad - comenzaron. Y cuando no existe una referencia de definición descriptiva, todos los preceptos asumen la necesidad de una descripción, y esto explica que la catalogación de tipos delictivos ofrezca una impresión de lluvia constante y granulosa de nuevas conductas descritas y penalizadas. Nuevos tipos descriptivos que son la regularidad, frente a la excepcionalidad de la definición descriptiva del tipo. La fragmentación responde entonces en sí misma a una función descriptiva de cada tipo perfilado; ahora no continúa la definición descriptiva de un determinado libro, sino que funda la descripción de tipos en múltiples normas. Como criterio de regularidad, los tipos descriptivos permiten mantener una política criminal semántica, sin definiciones ni siquiera descriptivas, por sí solos, como puede verse 
en Navarra. En definitiva, no hay una técnica normativa de recreación pictórica de las conductas criminales en el Derecho penal moderno, sino una técnica fotográfica.

Pero el respeto a esta técnica fotográfica implica una preconcepción semántica de los tipos delictivos, una comprensión fácil de su contenido. En parte se debe a la pura descripción, a su plasticidad. En parte, a la utilización de sustantivos y verbos preconocidos, entre el lenguaje jurídico y el lenguaje común. Es sólo entonces cuando puede descubrirse que la asistematicidad o protosistematicidad resulta quizá sólo aparente, o que la sistematicidad se logra por inducción y no por deducción. A ella sirve la preconcepción lingüística y la multiplicación descriptiva. La preconcepción lingüística remite por supuesto a la terminología conceptual del ius commune, donde el jurista ha descubierto a priori las palabras jurídicas y su significado. En realidad, las palabras jurídicas forman parte del equipaje cultural del redactor y manipulador de las normas, y por eso las normas no describen conceptos, sino que los usan, y por eso el uso legal puede llegar incluso a despreocuparse de cierto rigor, porque el significado previo ya se encuentra sedimentado y ahora el habla de la ley adquiere otro fin funcional y político. Por otra parte, la literatura jurídica parte y a su vez recoge ese vocabulario jurídico, ese diccionario jurídico, y remite en contraste de forma continua a la opinio communis doctorum. Léase la literatura jurídica antes que la ley, o la literatura jurídica a continuación de la ley, poco importa, porque la comunión entre diccionario y uso de la lengua jurídica está garantizada. Además, la literatura jurídica - a menudo como eco del ius commune - confirma lo que aquí se supone: la posibilidad, evitada en la normativa, de la definición pura. Ciertamente, quien piense que no cabe una definición de tipos delictivos sino por descripción, encontrará sin embargo en la literatura jurídica sobrados ejemplos de que la definición pura, como punto de arranque, interesa. Es cierto que la definición tiene que ser descriptiva cuando se define un acto; pero el dicitur demuestra que la definición se diferencia ontológicamente de la descripción, y así lo confirma el hecho de la cristalización, a través del dicitur, de categorías subjetivas u objetivas. Pues bien, el camino del dicitur y de la categorización es un camino doctrinal que no sigue el camino de la ley.

Así podría entenderse que, en realidad, no hay sólo una sistematicidad oculta que se ilumina por inducción. También la hay por deducción. Lo primero es lo regular, lo segundo lo excepcional, así como la definición descriptiva era lo irregular y la lluvia normativa descriptiva lo regular. La descripción de tipos delictivos, o la definición descriptiva de tipos delictivos, en la normativa moderna, parte de un lenguaje institucional previo. Las normas no definen los tipos delictivos propiamente porque ya están definidos, e incluso puede que no se precise su penalidad porque ya esté precisada: precisada en el ius commune, o en la literatura jurídica del ius proprium. Desde el punto de vista del lenguaje, el ius commune y el ius proprium —entendido como 
tradición jurídica propia de un lenguaje y como la doctrina propia - son el campo desde el que se deduce una multiplicidad de tipos delictivos que utilizan un vocabulario ya preconocido para proceder a la descripción de viejas o nuevas conductas punibles. La ley no crea el lenguaje técnico, antes bien lo emplea y le da (crea) un uso concreto y determinado. En este sentido, las definiciones descriptivas son un recordatorio, porque la lógica de la persistencia temporal — así de un lenguaje - conduce a los tipos descriptivos directamente; si los tipos delictivos son nuevos - como en los delitos de germanía - puede que se ofrezca un contenido descriptivo para su acotamiento semántico. Y una vez multiplicada la descripción en tipos delictivos a través del uso del lenguaje jurídico, la complejidad que estas descripciones alcanzan levanta por inducción una sistemática, o dota de una mayor densidad a la sistemática también arrastrada de la tradición.

La sistemática deductiva/inductiva a la que aquí se alude no es una estructura en puridad, sino más bien una relación de secuencias, porque ya no la normativa legal - centrada en el uso de la terminología - sino ni tan siquiera la literatura jurídica más preocupada por el significado convencional - abandonan un ritmo de problematicidad, de tópica y de casuismo. Empero, el orden de la escritura, la propia formulación de casos, en el commentarium, termina por aglutinar problemas que ofrecen un significado completo, y en el tractatus hay una composición previa, un orden deliberado de instituciones. La misma ley, cuando adopta un criterio más cercano al significado convencional que al uso político — más cercano a la literatura jurídica que al estilo de la preceptiva legal_-, como sucede en las Partidas, presenta estas secuencias: por ejemplo, la que enlaza homicidio/herida/fuerza/robo/hurto/daño; así como ciertas categorías - valga el hurto impropio - siguen este camino de precisión dogmática. Sin embargo, el uso de estos términos en la normativa del ius regium ofrece al fin la sensación de que las nociones, eventualmente, no están incomunicadas, pueden confundirse, y de que los significados trafican, sin que al mismo tiempo la secuencia conceptual e institucional, en definitiva, sea demolida, a la manera en la que el lenguaje común —un lenguaje técnico-común, en este caso- subvierte pero no yugula la gramática.

Se acerca un ejemplo concreto y significativo que ilustra estos problemas de la sistematicidad penal, tomado de las Variae resolutiones de Antonio Gómez ${ }^{5}$, un autor al que nadie negará en su doctrina una claridad meridiana en la exposición teórica y una preocupación que nunca desfallece por el contraste con la práctica ${ }^{6}$. Pero antes hay que tener en cuenta lo siguiente: la incorporación de la literatura jurídica —entiéndase que aúna la del ius commune y la del ius proprium — para la constatación de

\footnotetext{
${ }^{5}$ Antonio Gómez, Variae resolutiones juris civilis, communis, et regii, tomis tribus distinctae, Matriti, typis Petri Marin, 1730.

${ }^{6}$ Antonio Gómez, Variae, III, 4: “[...] quodlibet delictum, ejus poenam, \& materiam magistraliter resolvam, tam de jure communi quam regio: In qua maxime insudavi per plures annos, tam eam legendo, quam etiam pauperibus captis \& incarceratis, adjuvando, \& in eorum defensionem practicando".
} 
un diccionario jurídico previo del que parten los tipos delictivos descriptivos, parecería ir en contra de una presunción sobre la que ni siquiera se ha discutido aquí: la tipicidad delictiva presume la normatividad legal, y sólo en la normatividad legal, por definición, florece la tipicidad delictiva. ¿He aquí una anacronía? ¿Debe alterarse el criterio conjeturado hasta ahora, consistente en limitar los tipos delictivos a la legislación, al descubrir que su sistematicidad evoca la tipicidad delictiva de la literatura jurídica? Esta pregunta es la que trae a escena a Antonio Gómez.

Por supuesto, en la Edad Moderna no se teoriza una tipicidad delictiva. Hay que convenir en que, en una u otra sede, literaria o normativa, se definen, sustantivamente o por descripción, los tipos de delitos: el problema está en si esta definición o descripción autoriza a formular abstractamente una idea de tipicidad cuando las fuentes no la elaboran. Éste es un problema, sin duda, puesto que no se trata de funcionar en estas páginas con un cuadro de los tipos delictivos - o de estudiar un tipo delictivopara lo que bastaría la presunción, sino de resolver si la idea de tipicidad, en forma abstracta, requiere sine qua non un soporte normativo para entenderla como tal, y de qué soporte se trata. Por lo tanto, se necesita combinar una concepción previa de tipicidad — habilitada por la laguna del concepto en el Derecho clásico- con una legitimación concreta a partir de su funcionamiento significativo en las fuentes de la época. La concepción previa puede ser perfectamente la que tienes asumida supra: tipo delictivo como tipo determinado por la ley. Ahora bien, Antonio Gómez valora cómo la práctica en materia criminal puede abocar tanto al ius regium cuanto al ius commune, esto es, tanto a la normativa cuanto a la literatura jurídica (por no entender estrictamente el ius Romanum o Canonicum, que se suman a ella): este ius y aquella lex son contrastados cuando Gómez se interroga sobre la pena imponible. Por lo tanto, la tipicidad delictiva se identificaría con la descripción/definición de tipos en un ius — regium y commune - que como concepto engloba así hipotéticamente normativa legal y literatura jurídica, y en consecuencia por un mundo elevado, hacia la sistematicidad consumada por suma de la tradición, la reflexión y la actualidad normativa, que viene a poner en tela de juicio, en la medida en que los dicitur residentes en el ius commune propiamente definen, la fragmentariedad descriptiva que considerábamos característica del Derecho penal clásico. Parece que la fragmentariedad descriptiva del Derecho penal clásico sería meramente una apariencia, debida más a la fragmentación de los vehículos formales de manifestación de las normas y al ritmo de manifestación histórica de las fuentes (comunes y propias), que a la forma de entender y expresar los tipos delictivos.

¿Es errónea, entonces, la defensa de un tipo delictivo descriptivo y fragmentario en la Modernidad? A despecho de la antiapariencia, no lo es, y no lo es porque la fragmentación no ha desaparecido por elevación. Y el motivo de esta afirmación es el siguiente: la elevación que parece requerir la tipicidad delictiva a partir del ius como concepto abstracto tiene que ser matizada por la comprensión concreta de la lex penal en el seno del sistema jurídico aun combinado de iura y lex. Y la prueba de 
que es así reside en que toda reflexión sobre el ius punitivo se somete a la consideración prevalente de la lex nova penal. Así, Antonio Gómez plantea el concurso de leyes penales en un análisis concreto de los mecanismos de sucesión temporal de las soluciones jurídicas punitivas, y sólo se refiere al ius commune para valorar la posibilidad de que la prioridad o posterioridad en el tiempo no suponga efecto corrector, mostrándose finalmente contrario a tal criterio, en virtud de la practica, y defendiendo, pues, que la ley penal posterior corrige la pena de la ley anterior. A continuación, plantea el problema de la laguna de la ley para remitirse a un arbitrio judicial secundum merita causae \& qualitatem negotii, ciñendo al ius regium (y a sus mecanismos oficiales subrogatorios de manifestación de la voluntad regia) la vía para colmar aqué1la. Sólo a continuación contrasta la lex regni con el ius commune, para plantear si en el caso de que la ley nueva del reino imponga una pena mayor o menor que la que impone el ius commune - vel per aliam legem regni, añade, significativamente- el juez puede elegir la pena: ciertamente, aunque de inmediato ofrecerá pautas de decisión, Gómez plantea el problema vinculándolo al arbitrio judicial, del que venía hablando en caso de laguna de la ley, es decir, extiende (en congruencia con la tradición visigoda y medieval) la dificultad que entraña la laguna a la dificultad que entraña la duda u oscuridad sobre la aplicación de la ley. An judex possit eligere \& ponere poenam quam velit? Vienen entonces los criterios sugeridos: cuando consta expresa o tácitamente que la ley regia corrige a la común - se permite aplicar entonces el término lex al ius commune (expresión que por supuesto seguirá manteniendo no obstante), quizá para subrayar que en el cúmulo normativo que el ius commune comprende la referencia ahora se concentra en fuentes de carácter legislativo equiparables a la lex regia, porque la naturaleza especulativa de la opinio communis doctorum queda al margen al menos formalmente-, entiende que, en tanto la ley común no imponga pena condigna \& principalis pro punitione delicti, ha de ser aplicada sólo la ley regia; y si consta que la ley regia quería corregir o acumularse a la ley común, entonces se impondrán ambas penas como si fuesen de una sola ley. Esto significa que la ley regia subsume la solución normativa de la ley común, por su autoridad y potestad preferente. A mayor gloria de la ley regia, en el caso de que no haya constancia expresa o tácita de corrección de la ley común, Gómez piensa que habrá de observarse la ley regia nueva: así vale hodie conforme a la ley primera de Toro, que excluye la prioridad del ius commune, al que sólo cabe recurrir cuando el ius regium - ahora no sólo la lex, porque sin duda el arbitrio judicial va incluido- no ha decidido expresamente el caso. En definitiva, el ius commune -o las leges communes - no está elevado respecto de la tipicidad delictiva fragmentada de las leges regias, y ni siquiera al mismo nivel, sino condicionado por un juicio concreto de absorción. No hay más que contrastar el tratamiento que recibe el ius commune en cuanto leges communes con el que recibe la necesidad de coordinación técnica entre la poena ordinaria iuris civilis y la pena impuesta in foro poenitentiali: en esta tesitura, en la que la dualidad de jurisdicciones marca la fricción entre sistemas jurídicos 
concretos, vigentes y efectivos, a un mismo nivel, la complejidad aumenta, y el encaje técnico se afina, según la naturaleza del delito (crimen de mixto foro), intervención precedente de una jurisdicción u otra, finalidad, naturaleza principaliter y condigna y complementariedad de las penas ${ }^{7}$.

También es muy relevante que, al terminar Gómez con una alusión al orden de prelación de fuentes de la ley primera de Toro, es decir, tras la confirmación de que las leyes concretas del Derecho del reino (con su fragmentariedad delictiva no derivada, sino original) constituyen el eje del sistema, la elaboración de su comentario sobre aquella ley taurina se efectúe introduciendo - claro que (no importa repetir) en defecto de la preferente ley regia, e incluso de las Partidas y la costumbre inmemorial - una ratio naturalis, no elevada sino subordinada jerárquicamente, desarrollada en términos primero de opinio communis doctorum y supletoriamente de aliqua probabilis opinio alicuius doctoris - concreción del ius commune como literatura explicativa de ese ius antepuesto en la prelación en calidad estricta de regium - , y en su defecto de argumentum alicuius legis vel iuris scripti in simili casu disponentis, lo que mantiene la consideración - absorbida (dígase otra vez) por la ley regia previa- de la literatura jurídica como razón natural a modo de ius commune o incluso de opinión singular pertinente, y rebaja las referencias a otros eventuales iura concretos (Romanum, v. gr.) por la vía de su abstracción (ius scriptum) con el límite de la analogía ${ }^{8}$.

Así queda probada ontológicamente la tipicidad delictiva fragmentada y descriptiva como propia del Derecho moderno. Es importante esta prueba porque su aceptación (aunque, en definitiva, acertada) sin prueba en la bibliografía histórico-jurídica, impediría contar con un fundamento teórico firme a la hora de afrontar otros problemas técnicos y epistemológicos. Por ejemplo, el del reconocimiento de la función del ius commune, desde la absorción y supletoriedad mencionada.

En el Derecho de Castilla, hay dos focos de ius commune relevantes, si atiendes al orden de prelación de la ley primera de Toro. Uno es el residente en las Partidas; el reconocimiento de sus leyes como oficialmente aplicables, en la ley taurina, entrañaría una hipotética nivelación de fuerza con las leyes nuevas del ius regium, mas éstas prevalecen de modo nítido, mediante la expresa subordinación del cuerpo partido en la escala jerárquica normativa, desde el ordenamiento de Alcalá (más allá de que, como se dijo, las definiciones descriptivas de las Partidas no son más frecuentes que los tipos delictivos meramente descriptivos). Otro foco evidente es el de la literatura jurídica, una opinio communis doctorum integrada por la doctrina en la prelación de fuentes, a raíz de la glosa y commentarium de la ley primera de Toro, a pesar de que ésta no la reconoce formalmente, o bien sí la reconoce de forma implícita

\footnotetext{
${ }^{7}$ Antonio Gómez, Variae, III, 21-25.

${ }^{8}$ Antonio Gómez, Ad leges Tauri commentarium absolutissimum, Matriti, typis D. Gabrielis Ramirez, 1768, pp. 4-6.
} 
como consecuencia de la derogación expresa de la pragmática restrictiva de los Reyes Católicos ${ }^{9}$. Lo que interesa aquí, desde el punto de vista de la tipicidad delictiva, es la interpretación de la subsidiariedad del ius commune: subsidiariedad sumada a la supletoriedad, o supletoriedad desde la subsidiariedad. En realidad, la subsidiariedad que interesa estudiar es una idea que puede considerarse ya expuesta en reflexiones antecedentes: el mecanismo de las definiciones de los tipos delictivos en la literatura jurídica - los quid sit, dicitur...- opera de manera subsidiaria respecto del mecanismo de las descripciones de los tipos delictivos que rige en la ley regia. La literatura jurídica ofrece una lectura de la ley regia, a menudo desde una perspectiva más amplia pero que desemboca inevitablemente en el hodie del ius regium. Cuando éste presenta lagunas, o indefiniciones, o su descripción tipificadora es insuficiente o ambigua, la literatura o doctrina jurídica puede colmar o resolver el problema. Esta función en nada contradice, sistémicamente, sino, más bien al contrario, deriva de la propia naturaleza de la tipicidad fragmentada.

Quizá sea oportuno el ejemplo de un caso concreto. Probado que la tipicidad delictiva tiene una referencia sustantiva de carácter legal — que le otorga su naturaleza propia, fragmentaria y descriptiva - y que en consecuencia el tratamiento tipificador de los delitos por parte de la literatura jurídica actúa con una función subsidiaria/supletoria, importa señalar los resultados a veces teoréticamente sorprendentes de este planteamiento. La fragmentación abre lagunas pero también verdaderos mares. Piensa en el delito de estupro. El delito de estupro no está legalmente tipificado: el estupro no es un tipo delictivo, si para la verificación del tipo delictivo se entiende probado que se requiere la cobertura de la ley vigente descriptiva o definitoria/descriptiva. Pero lee entonces a un autor tan preocupado por la determinación de las figuras delictivas, y de sus penas en los distintos iura, como Francisco de Pradilla, en la Suma de las leyes penales ${ }^{10}$. Nota que Pradilla hace una relación muy completa de los tipos delictivos, de tipos delictivos ciertamente tipificados en sentido legal estricto. Es notable la plenitud de su recorrido, que abarca delitos de toda naturaleza, un catálogo que absorbe en gran medida el surtido que se extrae del rastreo del contenido tipificador de las leyes del ius proprium ${ }^{11}$. Pues bien, en este catálogo tan com-

\footnotetext{
${ }^{9}$ Para esta cuestión, vid. Carlos Petit, "Derecho común y Derecho castellano. Notas de literatura jurídica para su estudio (siglos XV-XVII)", Tijdschrift voor Rechtsgeschiedenis, 50, 1982, pp. 172-174, 183-185. ${ }^{10}$ Francisco de Pradilla, Suma de las leyes penales, Madrid, Imprenta del Reyno, 1639, f. 3r-v.

${ }^{11}$ Y aquí sí que se aceptará una nueva referencia expresa a las páginas de La tipicidad, op. cit., passim, con las que cabe comparar el resto de esta nota. Se transcribe a renglón seguido la relación delictual de Francisco de Pradilla, Suma, ff. 141r-142r, Tabla de los delitos, y casos que el derecho comun, y deste Reyno castiga concierta, y determinada pena, que en esta suma, y practica se contienen, por lo que en efecto interesa a cuanto se está diciendo, y también a lo que se dirá más adelante. La tabla reza así: "de la heregia, y hereges", "De los blasfemos", "Del crimen laesae Maiestatis", "De los que blasfeman del Rey", "De lo que fuerçan, y desfloran virgenes", "De los que tienen accesso con Monjas", "De los raptores, y que lleuan mugeres", "Del incesto, y su pena", "Del delito del adulterio", "Del crimen de lenocinio, y de los alcahuetes, y encubridores", "Del crimen nefando de la sodomia", "De los que casan dos
} 
pleto, y tan homogéneo con un catálogo de tipicidad delictiva legal, aparece un delito de estupro que cuenta, como pórtico, con su dicitur ("se dize, coito ilicito, y reprouado, por el qual se desflora a la muger virgen, y doncella"). Dada la ausencia del estupro en una relación de tipicidad delictiva legal ad intra, podría considerarse que se trata de un ejemplo claro de la necesidad de apertura sistémica del concepto de tipicidad para rellenarlo con la tipicidad delictiva doctrinal, reduciendo o aminorando la supuesta esencia de la fragmentariedad. Pero ya queda dicho que no crees en un desvanecimiento de la fragmentariedad por causa del ius commune ni de ninguna otra dilatación sistémica ${ }^{12}$. Esta idea es la que habrá que confirmar en el planteamiento de Pradilla, además de encontrar en él una explicación o una visión del funcionamiento de la subsidiariedad.

Tras el dicitur, Pradilla relaciona, a propósito del estupro, $1 .^{\circ}$ la pena ordinaria en el Derecho canónico, $2 .^{\circ}$ la pena que ha impuesto el uso, conforme a la opinio communis doctorum, $3 .^{\circ}$ la pena establecida por el Derecho civil, $4{ }^{\circ}$ la pena del acceso carnal de criado con parienta, doncella, nodriza, ama o sirvienta en casa de su señor, según las leyes del ius regium recogidas en la Nueva Recopilación, y 5. (en círculo) la pena canónica para el caso de estupro cometido por el clérigo. Pues bien, Pradilla elabora un trabajo sustantivamente penológico más que delictual. Se dirá que no puede ser de otra manera cuando el supuesto tipo delictivo ya está previamente concretado: el estupro. Sin embargo, es claro que en su desarrollo se incluyen figuras asimilables al estupro pero que no son estrictamente, conforme al dicitur, estupro, sino afines. Precisamente el tipo delictivo legal del acceso carnal con sirvienta en la casa del señor no es, forzosamente, un estupro, para lo que basta pensar que el tipo delictivo funciona aunque la criada no sea virgen si el acceso carnal tiene lugar en la casa del señor, y que un acceso carnal con la criada fuera de la casa del señor al menos hará perder a la pena su naturaleza ordinaria (legal): en este caso, las circunstancias que describen el tipo le otorgan una naturaleza propia como tipo delictivo, a las que no se adapta bien — aunque mantenga la afinidad - el dicitur del estupro. El dicitur

vezes", "De los que son amancebados", "De los adiuinos, y hechizeros, y bruxos", "de los que matan, y del homicidio", "de los que matan a sus padres espirituales, y naturales, y de los parricidas", "de los que cometen homicidio, y matan con veneno, o yeruas", "de los que matan, a traycion", "de los que matan por assasinos, y hombres alquilados para que maten", "de los que desesperan y matan", "de los falsarios", "de testigos falsos", "de los que hazen moneda falsa", "de los que vsan medidas y pesos falsos", "de los que suponen partos fingidos", "de los que mudan los mojones", "de los que dexan a otros sus hijos", "de los hurtos, y ladrones", "de la simonia, y su pena”, "de la vsura, y de los logreros", "de los perjuros", "del sacrilegio, y su pena", "de los que ponen fuego, y queman las Iglesias, casas, montes, y mieses", "de los plagiarios, que roban hombres", "de los abigeos, y ladrones de ganados", "de los sediciosos, y alborotadores", "de los salteadores, y robadores", "de los que hazen fuerça publica", "de los que tienen carceles particulares", "de los que impiden la sepultura a los muertos", "de los que deshazen, y quebrantan los sepulcros de los muertos, y los desentierran, y despojan de los vestidos", "de los que injurian a otros por obras, o palabras", "de los descomulgados, y su pena", "de los que hazen matrimonios clandestinos", "del delito del juego, y su pena", "de los que vsurpan los bienes de la Republica”.

${ }^{12}$ Por eso se insistía supra en la necesidad de una previa demostración de esta máxima. 
del estupro se adapta perfectamente, empero, a los supuestos para los que establece penas el Derecho romano-canónico. Ahora bien, incluso en una exposición tan concreta y lacónica como la de Pradilla, estas penas congruentes con una definición rigurosa del estupro son citadas para de forma inmediata apuntar su exclusión: su desuso. Subyace entonces una razón de legitimidad jurídico-política que explica la automaticidad del descarte del Derecho romano-canónico: este ius no implica un tipo delictivo, y en este sentido la relación penológica permite la exclusión con facilidad y sencillez de aquellas penas que carecen del amparo de un tipo delictivo legal estricto; no sucedería lo mismo si se trata de una pena impuesta por el ius regium: en este caso la fuerza del desuso requeriría otra ratio o quizá, mejor, la misma ratio reforzada. Porque hay en efecto una misma ratio que permite tanto la exclusión de penas del Derecho romano-canónico cuanto una hipotética derogación de la pena del ius regium: la ratio del uso nuevo. Y el calificativo nuevo es engañoso; en realidad no es la novedad la que permite detectar un desuso anulador de soluciones punitivas. Es el uso en sí, con su naturaleza. Y resulta que su naturaleza remite a la tipicidad delictiva legal.

El uso remite a la tipicidad delictiva legal. Es verdad que en Pradilla el uso punitivo del estupro está reforzado por la opinio communis doctorum, el ius commune, mas, en puridad, la opinio sólo traslada, confirma, remata el uso. No es un uso que nace de la opinio, sino que la opinio constata y respalda. En cuanto al enlace con la tipicidad delictiva legal, es plausible porque el uso es fuente de la costumbre, y la costumbre deudora de la ley. El uso es el factum, un hecho en el tiempo cuya conformidad con la razón garantiza la opinio $^{13}$, y del que nace la costumbre, que es el ius. Pero este ius que es la costumbre, cuando las Partidas se preguntan quién puede ponerlo, se explica que está sujeto a la autorización o no contradicción del señor (entiéndase el rey, hic et nunc) ${ }^{14}$; y por lo que a su fuerza jurídica se refiere, la costumbre sirve en caso de laguna legal, y con virtud interpretativa de la ley actual y abrogadora de la ley antigua, fundamentándose en el consentimiento del rey ${ }^{15}$. Este control $a$

\footnotetext{
${ }^{13}$ Partidas 1.2.2: "Fazer se deue el vso de manera que sea a pro comunal, e sin daño, e no deue ser fecho a hurto, ni escondido, mas en manera que lo sepan, e se paguen los que fueran conoscedores de razon, e de derecho".

${ }^{14}$ Partidas 1.2.5: "E tal pueblo como este, o la mayor partida del, si vsaren diez o veynte años a fazer alguna cosa, como en manera de costumbre sabiendolo el señor de la tierra, e no lo contradiziendo, e teniendolo por bien, pueden la fazer, e deue ser tenida, e guardada por costumbre, si en este tiempo mismo fueren dados, concegeramente dos juyzios, por ella, de omes sabidores, e entendidos de juzgar".

${ }^{15}$ Partidas 1.2.6: "Fuerça muy grande ha la costumbre, quando es puesta con razon, assi como diximos, ca las contiendas que los omes an entre si, de que non fablan las leyes scritas, pueden se librar por la costumbre que fuesse vsada sobre las razones sobre que fue la contienda, e aun ha fuerça de ley. Otrosi dezimos que la costumbre puede interpretar la ley quando acaesciesse dubda sobre ella, que ansi como acostumbraron los otros de la entender, ansi deue ser entendida e guardada. E aun ha otro poderio muy grande, que puede tirar las leyes antiguas que fuessen fechas antes que ella, pues que el rey de la tierra lo consintiesse vsar contra ellas tanto tiempo como sobre dicho es, o mayor".
} 
priori o a posteriori del rey sobre la costumbre es en definitiva el control de la ley, la absorción de la costumbre por la ley, porque la ley es el precepto que el rey recibe, ha o da como tal, en virtud de su potestad, y la costumbre una norma más sujeta en sus virtudes a su reconocimiento por la ley (de ahí también la atribución a la costumbre de fuerza de ley); por otra parte, la ratificación judicial de la costumbre (a modo de requisito genesíaco) remite al arbitrio judicial cuya incardinación en el ius regium e intimidad con la ley ya ha quedado comentada a propósito de la doctrina de Antonio Gómez. Por decirlo de forma tajante, el uso - por las vías de la opinio y la costumbre- catapulta hacia la ley. Hacia la ley que es la clave de la tipificación delictiva. Y por esta comunión entre el uso y la ley, de cajón la resistencia a la derogación por desuso tiene que ser menor en las penas impuestas por iura que carecen de la efectividad tipificadora legal estricta. Son como penas no cubiertas por la tipicidad, a la intemperie. Donde hay palabra de estupro, no hay tipicidad delictiva, y hay penas como estatuas de sal. Ahora bien, a pesar de todo, el estupro parece fantasmagóricamente incorporado al lenguaje jurídico de la tipicidad legal, y esto es así porque si bien el uso ha dado lugar a una pena en correspondencia con una conducta que la ley no tipifica, a la sazón ha cristalizado no obstante la pena del estupro, como si la cristalización fuera al uso lo que la tipificación a la ley, luego la pena ha quedado habida por la ley, y por lo tanto la pena usada, ónticamente legalizada, y de ahí surge en consecuencia el ansia de remisión a un concepto delictivo que hay que fijar y cuyo significado hay que determinar. Es entonces cuando tiene valor el vínculo con el ius commune. El ius commune suministra — a modo de diccionario- la precisión terminológica y el dicitur del concepto por el que la pena del uso (de la ley) clama; la pena ansía el concepto y lo husmea, y al final localiza su fruto. La subsidiariedad es este mecanismo gramático. Bien es verdad que, entonces, una vez identificado el concepto y su significado, que la pena usada reclamaba, al suceder esto y una vez sucede, hay una caída hacia la concreción otra vez de la pena del uso, un descendimiento a la maraña de las descripciones de las leyes. Es decir, todo retorna y se precipita en el mundo de la fragmentariedad, que en ningún momento, a la postre, se ha visto perturbado. Y por lo tanto el paisaje jurídico-criminal, en general, enseña tipos delictivos evidentes a los que ahora acompaña algún tipo penal o punitivo — en sentido estricto- que carece (como el estupro) de tipo delictivo, pero que no obstante puede ser entendido y aplicado por la vía del uso y gracias a la subsidiariedad del ius commune (inspirador e intérprete del uso que el arbitrio judicial respalda). Es significativo entonces que la literatura jurídica, que se encuentra en una posición idónea para acumular y contrastar soluciones jurídicas de iura diversos, razone frecuentemente problemas relativos a tipos concretos desde la perspectiva de la pena a la que tenetur, porque el tipo penal es aquello que mejor cuadra y menos falla entre tipos delictivos penalizados y tipos penales sueltos. Antonio Gómez, por volver a él, medita sobre el homicidio cualificado no tanto en términos conceptuales de tipicidad delictiva - pero no evita su especificación teorética: parricidio, asesinato, envenenamiento, suicidio, etc.— cuanto 
en términos de aplicación o no de la pena de muerte ${ }^{16}$. Nada debe extrañarte pues que en este aluvión de argumentos por razón de la pena, haya por lo común penas encapsuladas en su tipo delictivo - tipo delictivo-penal - y penas que restan al aire o simples tipos penales.

Hay tipos delictivo-penales, y tipos meramente penales, tal y como, de hecho, hay también meros tipos delictivos, tipos delictivos truncados, sin tipo penal conexo o, mejor, ordinario: delitos sin penas determinadas. El caso es especialmente llamativo en el Derecho de Navarra y de la Corona de Aragón. La muerte o prisión del rey (y el consejo para delinquir) en Navarra, el prendimiento judicial si no tiene lugar por causa de maleficio flagrante en Aragón, o el prendimiento, fuerza o extracción violenta contra el asilo, y la falsedad de pesos y medidas, en Cataluña, figuran como normas penales admonitivas, en algunas de las cuales cabe presumir la pena (el crimen de lesa majestad humana) mientras que en otras la indeterminación plantea la incógnita de la pena aplicable. Desde luego, esta ausencia de tipos penales puede explicarse de una forma similar a como se razonaba a propósito de supuestos tipos delictivos rigurosamente no tales (el estupro), en virtud de la subsidiariedad definitoria o descriptiva del ius commune. En el caso del Derecho de Navarra y de la Corona de Aragón basta activar el reconocimiento de la supletoriedad del ius commune: por costumbre y reconocimiento expreso en Cortes a finales del siglo XVI en el caso de Navarra, y por vía de sentido o razón natural y de equidad, o también de reconocimiento expreso junto al Derecho romano-canónico, en los casos de Aragón, Cataluña, Valencia y Mallorca, desde las fuentes bajomedievales. Sin duda, la subsidiariedad respecto del tipo penal funciona con mayor sencillez especulativa que respecto del tipo delictivo: previsto el tipo, el rastreo del orden de fuentes localiza la pena y la incorpora por tendencia centrípeta de la prelación normativa. Ahora bien, el propio ius commune, y fundamentalmente, con mayor vigor, las expresiones sinónimas que vienen a acompañarlo de continuo — razón natural, sentido natural, equidad—, ofrecen la vía ya conocida de determinación de la pena aplicable: el arbitrio judicial, instrumento actualizador o concretador espejo del uso de la política criminal. Un arbitrio judicial que no sólo mitiga penas en función de las circunstancias, sino que también colma lagunas normativas. La pena extraordinaria remite entonces, en virtud de los mecanismos político-administrativos de subrogación, a la legitimación habilitadora del rey, y en consecuencia al mundo de la ley, si se quiere no manifiesta, sino en ciernes, si se quiere no generativamente, sino consumativamente.

El arbitrio judicial no genera tipos delictivos, como una razón más del carácter estrictamente legal del tipo delictivo. Sólo el rey recibe, ha o da por ley, y no sus oficiales. Pero los oficiales tienen una capacidad decisoria que la ley regula y limita a la tipificación de su naturaleza extraordinaria y arbitraria. El tipo penal no es legal por definición: sólo la pena ordinaria es legal, como la doctrina se encarga de presumir

\footnotetext{
${ }^{16}$ Antonio Gómez, Variae, III, pp. 98-106.
} 
y repetir; la pena extraordinaria responde a una habilitación que ni innova en la legalidad delictiva, ni la contradice, en la medida en la que se limita a completar, por la vía de la pena, el tipo delictivo que no ha sido configurado punitivamente o cuyas circunstancias de consumación han alterado la previsión legal. Llegas así a una tesitura en la que se entiende también que el uso, aun rectificador a favor del ius regium - y necesitado de ratificación judicial como costumbre-, no se vuelque primordialmente en la elaboración de tipos delictivos, sino de tipos penales: es la pena - la pena usada - la que cristaliza el uso. Mientras el concepto no tipificado delictivamente por la ley es incorporado a la ley estrictamente como voz - como lenguaje traducido técnicamente - en virtud de la subsidiariedad significativa de otras fuentes, el tipo penal constituye en sí mismo no una pura determinación lingüística sino en efecto una tipificación, pero una tipificación estrictamente penal. Una vez más, la tipicidad delictiva, con su fragmentariedad, queda en manos de la ley, amén de las funciones subsidiarias o complementarias que cumplan otras fuentes jurídicas ${ }^{17}$.

Y por cierto que algo puede añadirse una vez advertido este tipo penal abierto: también, de otro modo, puede quedar abierto el tipo delictivo. Deliberadamente abierto, por razones de política criminal. (Se trata de un fenómeno acorde con la fragmentariedad de la tipicidad.) Así sucede precisamente en una tipicidad delictiva característica de la Edad Moderna: los delitos de germanía. Las leyes promulgadas contra los ladrones otorgan la gravitación del tipo a una razón subjetiva: se presumen por supuesto conductas — hurtos y robos, tenencia de armas, asaltamientos, juegos prohibidos, etc.- - pero la categorización subjetiva delictiva (el retrato del profesional del delito) lo absorbe todo y se constituye en causa suficiente de la penalidad. Es más, el tipo penal determinado se extiende a tipos delictivos asimilables con una razón también de subjetividad: los vagamundos, los rufianes, se suman al círculo de los ladrones. Hay consecuentemente también entonces una fragmentación del tipo delictivo en una constelación de sujetos próximos, cuyas actividades presumidas e hipotéticas se confunden. De la misma manera, el tipo delictivo puede quedar abierto en los delitos de germanía a través de una razón objetiva: ambientes sórdidos de prostitución, casas de juego, tráfico de armas, conciliábulos de organizaciones criminales; la mera localización criminal de estos focos de delincuencia — allí hubo, hay o habrá delitoactiva el tipo delictivo-penal.

He aquí pues demostrada y explicada la tipicidad legal descriptiva y la fragmentariedad del delito en el ius regium de la Modernidad, y la función gramatical de la subsidiariedad del ius commune, y tipificadora de la pena de la subsidiariedad del uso y el arbitrio judicial.

\footnotetext{
${ }^{17}$ De hecho, a pesar de la completa relación de Francisco de Pradilla vertida en nota pasada, la literatura jurídica se siente libre de relacionar tipos delictivos conforme a un propio criterio de exposición y síntesis. Antonio Gómez, Variae, III, caps. 2-7, vuelve a ser revelador, con esta ordenación original: crímenes de lesa majestad divina y humana / homicidio (con una remisión final interna e incongruente al adulterio) / hurto / injuria / estelionato.
} 
Al margen de que toda afirmación necesite, por muy indiscutida que se encuentre, una verificación argumentada y concluyente al servicio de su mera persistencia así la tipicidad descriptiva y fragmentaria de los delitos en la Edad Moderna- hay una utilidad derivada de toda probanza que se concreta en la elusión de equívocos. Por ejemplo, un entendimiento de la descriptividad y fragmentariedad del tipo delictivo moderno ilumina automáticamente contra el error sorprendente de la teoría de la inexistencia de circunstancias modificativas de la responsabilidad criminal en la evolución histórica del Derecho.

Esta sorprendente hipótesis de Emma Montanos Ferrín — referida a las agravantes- parte de un prejuicio de anacronía ${ }^{18}$, esto es, el recelo del historiador ante un arsenal conceptual contemporáneo cuya aplicación en la interpretación de un período histórico precedente se sospecha una lectura anacrónica. ¿Las circunstancias modificativas de la responsabilidad criminal son ahora aquellos casos que modificaron el tenetur a la ley penal o la oscilación entre la pena ordinaria y extraordinaria? La respuesta negativa - el prurito de respeto a la antigualla - corre el riesgo de olvidar que toda construcción histórica traiciona la armazón conceptual de las fuentes, por principio, y las consecuencias que se derivan de este límite realista. Es evidente que la terminología distancia el lenguaje del historiador del lenguaje de la fuente, y que en esta tesitura el historiador ha de usar la máscara de un habla a la manera de la fuente, mas el habla rigurosa no consiste en una (imposible y superflua) reproducción passim sino en la capacidad de expresarse de manera pertinente respecto de la fuente y dando origen a una composición cohonestable con el cúmulo de fuentes. Como el actor, no se trata de convertirse en el personaje, sino de convencer como tal personaje. Lo que está en juego en el trabajo del historiador no es una supuesta reconstrucción del pasado en un sentido real, sino la lectura y exposición de las fuentes pretéritas con una máquina de interpretación y traducción que resulte competens, no contradictoria ni innovativa, y resignificativa de aquello cifrado en el embotellado mensaje de la fuente. Así como el traductor del latín de Horacio asume la lejanía superficial que la convención del diccionario no disimula, y se honra con la pretensión de trasladar un ritmo, una riqueza significativa y un estilo o ánimo de expresión que dan por cumplido su esfuerzo, el historiador sangra en un análisis del objeto que la fuente asume, bajo la máscara de su lenguaje, en orden a la comprensión del contenido y a la manifestación de su espíritu, y dado que esa máscara la ha confeccionado él, y no la

\footnotetext{
${ }^{18}$ Emma Montanos Ferrín, "La inexistencia de circunstancias agravantes en el Derecho histórico", E. Montanos Ferrín - J. Sánchez Arcilla, Estudios de Historia del Derecho criminal, Madrid, 1990, p. 77: "Esta investigación se centra en el estudio de las 'circunstancias agravantes' en la historia del Derecho español. El problema resulta especialmente delicado si lo que se pretende — como en este caso- es realizar una valoración de los textos que proporcionan las fuentes sin plantear problemas anacrónicos ni incurrir en la adopción de conceptos dogmáticos contemporáneos”.
} 
fuente, aun con los mimbres y materia prima de la fuente, no deja de ser propiamente una máscara, y por eso en definitiva no cabe prescindir de la máscara pero simultáneamente la máscara no puede servir a un engaño que permita la amnesia desde la máscara - todo el mundo sabe que el historiador no es la fuente- $-\mathrm{y}$ debe permanecer tensa hacia la pertinencia de su actuación, de lo que representa. El mero hecho de la acumulación de problemas con terminologías diversas intertemporales - aun para la detección posterior de anacronías - en la faena histórica, señala una estimulación relacional a priori de los problemas: la anacronía, pues, no surge espontáneamente, sino que sólo es verdadera cuando obedece al acuse de la impertinencia. La pertinencia es un problema que absorbe el de la anacronía ${ }^{19}$.

${ }^{19}$ La pertinencia es un problema que excede con mucho las reflexiones de estas páginas. En todo caso, merece la pena apuntar algún ejemplo de lo que se quiere aquí decir con pertinencia. Para ello es recomendable el trabajo de José Sánchez-Arcilla Bernal, “¿Arbitrariedad o arbitrio? El otro Derecho penal de la otra Monarquía [no] absoluta”, en J. Sánchez-Arcilla Bernal (investigador principal), El arbitrio judicial en el Antiguo Régimen (España e Indias, siglos XVI-XVIII), Madrid, 2012, pp. 9-46, en el que se procede a una crítica de las conclusiones de Tomás y Valiente en su célebre obra citada supra. Interesa ahora no tanto lo criticado como la crítica en sí, en lo que tiene de tratamiento de un problema de pertinencia. Podría sintetizarse en el sentido de que Tomás y Valiente acusa al sistema penal del Antiguo Régimen de falta de imparcialidad, en el sentido de una decantación de los instrumentos procesales probatorios hacia la condenación del reo: tal sería la arbitrariedad frente a la que Sánchez-Arcilla opone el arbitrio - ciertamente un mecanismo nunca antilegal sino legitimado en los mecanismos de subrogación político-jurídica de los oficiales en la voluntad del rey y sujeto a la ley- entendido como fuente de la pena extraordinaria que, conforme efectivamente a la doctrina (dejo al margen la documentación judicial ratificadora de este criterio, que constituye una parte importante del artículo en cuestión), se expresa en la línea de una mitigación de la pena ordinaria legal (en virtud de problemas en la operatividad del tipo delictivo a los que el presente trabajo se ha referido ya). De alguna manera, en Tomás y Valiente hay una idea genérica: la dureza represiva de la justicia del Antiguo Régimen; y una idea específica: el abuso del arbitrio judicial y la pena extraordinaria como una manifestación de la dureza represiva (cf. v. gr. Tomás y Valiente, El Derecho penal, p. 379); en Sánchez-Arcilla hay una idea específica: la pena extraordinaria como un mecanismo de mitigación de la pena ordinaria; que redunda en una cuarentena de toda prejuzgada dureza represiva. Aunque aparentemente ambos planteamientos son opuestos, hay una asimetría reseñable al tomarse distancia de la polémica: si la pena extraordinaria es mitigadora, su abuso no puede conducir a una mayor dureza represiva, pero a su vez la dureza represiva no tiene por qué emanar de un abuso del arbitrio judicial y la pena extraordinaria, sino de la aplicación de la pena ordinaria legal, porque la aplicación habitual de la pena ordinaria legal es un instrumento básico con el que puede fundamentarse tanto una política criminal represiva dura cuanto una suave, dependiendo del grado de inquisición. La lectura de Francisco de Ariño, Sucesos de Sevilla de 1592 a 1604, Sevilla, 2005; Jerónimo de Barrionuevo, Avisos del Madrid de los Austrias y otras noticias, Madrid, 1996; Luis Cabrera de Córdoba, Relaciones de las cosas sucedidas en la Corte de España desde 1599 hasta 1614, Salamanca, 1997; Gerónimo Gascón de Torquemada, Gaçeta y nuevas de la Corte de España desde el año 1600 en adelante, Madrid, 1991; Ángel González Palencia, Noticias de Madrid. 1621-1627, Madrid, 1942; Francisco Henríquez de Jorquera, Anales de Granada: descripción del reino y ciudad de Granada, crónica de la reconquista (1482-1492), sucesos de los años 1588 a 1646, Granada, 1987; Antonio Moreno de la Torre, Diario. Zamora, 1673-1679. Vida cotidiana en una ciudad española durante el siglo XVII, Zamora, 1990; José Pellicer, Avisos. 17 de mayo de 1639-29 de noviembre de 1644, París, 2002; Luis Zapata, Miscelánea o varia historia, Llerena, 1999, entre otros títulos de crónicas, avisos y noticias de 


\section{El caso es que Montanos Ferrín pone en tela de juicio la existencia de circunstan-} cias agravantes en el Derecho histórico, lo que ha de entenderse conforme a la idea

episodios sociales con activa intervención de la justicia, ofrece un panorama de delincuencia aguda y violencia social a la que la maquinaria administrativa de represión responde muy activamente y con dureza, y al mismo tiempo esta represión no parece derivar en su mayor medida de un abuso (hipotéticamente no mitigador, contra su naturaleza misma) del arbitrio judicial, sino de un contundente ejercicio de la legalidad penal. Así las cosas, si se prefiere encontrar el eje de esta controversia en el grado de inquisición, se perfila ciertamente una clave para el replanteamiento del asunto. En sede procesal, Tomás y Valiente aprecia una orientación dirigida predominantemente al castigo, que Sánchez-Arcilla impugna. Con esta deriva, válgate la síntesis de la afirmación de este último historiador, "El arbitrio judicial", p. 18: "Más sorprendente es la afirmación de Tomás y Valiente respecto a la inexistencia de la presunción de inocencia a favor del reo. Si no recuerdo mal, el primero en postular el principio de presunción de inocencia fue Beccaria en 1764, posteriormente recogido en el artículo 9 de la Declaración de los Derechos del hombre y el ciudadano de 1789. ¿Cómo iba a estar recogido dicho principio en la legislación castellana de los siglos XVI al XVIII?". Desde un punto de vista formal, el argumento es claro, pero, desde un punto de vista material, al discutirse el grado de inquisición, lógicamente el problema se plantea desde otro punto de vista: ¿el proceso está concebido como una presunción de inocencia, que judicialmente ha de quedar destruida, o por el contrario como una indagación de la culpabilidad, cuya frustración redunda en prueba de inocencia? Las quiebras del efecto de cosa juzgada y del principio ne bis in idem, de las que se ocupó María Paz Alonso Romero, El proceso penal en Castilla. Siglo XIII-XVIII, Salamanca, 1982, pp. 262-265, parecen dejar abierta la indagación de la culpabilidad, y jugar a favor por lo tanto de este criterio. Mas dejando al margen este aspecto técnico, cabe echar un cuarto a espadas con el caso concreto del que se ocupa Alfonso de Azevedo, Commentarii, p. 447: cuando aparece un cadáver, rige una presunción contra dominum domus vel contra vicinos, pero el juez ha de valorar, para no castigar a un inocente - ne innocens Dominus puniatur, exactamente - , la presencia o ausencia del dueño en la casa, si aliud pudo intervenir en la muerte, si el difunto tenía enemigos, la buena fama del dueño o si le precede una conducta similar, o la dimensión de la casa, para valorar si la muerte pudo producirse en un lugar $\sin$ que lo supiera el dueño ("quod iudex omnino pro posse tenetur inquirere si alius eum occidit, ne innocens Dominus puniatur, \& itidem scire an hic Dominus domus sit solitus similia facere vel non"); la excusación de la pena de muerte se produce ex qualibet causa, y no ha de imponerse ex praesumptionibus etiam violentissimis. Estos argumentos, ¿implican una presunción de inocencia o una indagación prudente y circunstanciada de la culpabilidad (en orden al no castigo del inocente)? Ten a este respecto en cuenta declaraciones más palmarias, como la de Bartolome Cepolla, Consilia criminalia, Venetiis, ad signum iurisconsulti, 1575, ff. 118v-119r: "Nam iudex debet de innocentia inquisiti quaerere $\&$ testes examinare, \& quando iudici constat de inquisiti innocentia etiam si sit absens \& contumax nec aliquis defendat eum debet iudex absoluere. [...] Et ideo ego intelligo dictum statutum dum dicitur quod habeatur pro confesso nisi per testes \& iura constet de eius innocentia quae praeualet \& quam iudex sequi debet”. La pertinencia en la interpretación se complica, y todavía podría discutirse la singularidad del supuesto en el que la valoración de la inocencia se manifiesta tan expresamente. Si se entiende que el ejemplo corrobora la indagación de la culpabilidad (la pena del homicidio parece regir no obstante su referencia debilitada), no es a partir de una inexistencia de la valoración de la inocencia; si se entiende que el ejemplo implica una presunción de inocencia, o bien se limita a este caso, o bien hay que contrastar la presencia o ausencia de tal preocupación en el resto de supuestos jurídicos, pero no puede decirse que no exista materialmente. Ludovico Careri, Practica causarum criminalium, Lugduni, apud Gulielmum Rovillium, 1562, p. 180v, plantea el supuesto de una riña en la que no es posible determinar cuál de los dos contendientes fue el primer agresor, a propósito de la licitud de la muerte causada en defensa propia, para optar finalmente por la absolución tanto si se trata de uno como de otro, con el siguiente razonamiento: “[...] quomodo ergo uterque damnari possit, esset enim iniustitia, ut propter peccatorem 
de que muchos de los delitos calificados con dichas agravantes no son los mismos idénticos delitos agravados sino delitos distintos de aquéllos que carecen de ellas. Late en este pensamiento un prejuicio - que se dice combatir a propósito de la agravante- acerca de la significación del término delito, y del término tipo ${ }^{20}$. Montanos Ferrín parte paradójicamente de una preconcebida y anacrónica concepción del tipo delictivo como tipo unitario. Considera la agravante en términos contemporáneos no extrapolable históricamente, empero la extrapola al excluir cualquier significado que no sea el contemporáneo (a pesar de que éste no interviene) ${ }^{21}$, y extrapola además la noción contemporánea unitaria del tipo delictivo. Si se tuviera conciencia de que el tipo delictivo moderno es fragmentario y descriptivo, se suavizaría esa diferencia hipotética entre agravantes y delitos distintos, porque la descripción de un tipo delictivo incluye la posibilidad de su sucesiva matización circunstanciada. De ahí que, efectivamente, no sólo en el Derecho romano, sino también en la doctrina moderna, tiendan a insertarse en la qualitas de la agravación factores muy diversos, como la condición del delincuente, el lugar y el tiempo, claves de ejecución o la reincidencia, porque en

damnetur innocens, melius erit ergo nocentem absolvere, quam innocentem condemnare, ratione enim incertitudinis, nemo damnatur". Parece en efecto que el problema de ajustar la orientación de la administración de justicia penal moderna, a partir de conceptos que implican una valoración de otro tiempo, no reside tanto en anacronías cuanto en razones de pertinencia.

${ }^{20}$ Por ejemplo, Montanos Ferrín, "La inexistencia", p. 92: "El Derecho visigodo nos ofrece una detallada y perfectamente sistematizada regulación de los llamados delitos contra las personas, más detallada que la romana, pero en su línea. Sin embargo, como hemos de ver también, la regulación de los delitos contra la propiedad, si bien está en la línea de la romana, aparece como desdibujada aquella construcción romana, casi de orfebrería, de la distinción de hurto y robo y de los distintos y matizados tipos de hurto; distinción que se conserva en crisis y diversidad de delitos que, aunque difuminados, se conservan como tales delitos y como debidos a 'circunstancias agravantes', que siguen sin existir. La legislación visigótica recoge delitos de muy diversa naturaleza y nos ofrece un completísimo mosaico en donde los más diversos comportamientos punibles adquieren carácter de delito".

${ }^{21}$ Montanos Ferrín, "La inexistencia", p. 102: "Del análisis del contenido de los distintos fueros se deduce la inexistencia de 'circunstancias agravantes', tal como hoy las conceptuamos, en la Alta Edad Media". El reproche se deshace cuando se admite, por ejemplo en p. 79, que la bibliografía iushistórica precisamente no parte del concepto contemporáneo: "Sin embargo, en la reconstrucción que del Derecho penal romano llevan a cabo Mommsen o Ferrini son continuas las referencias y alusiones a diversos tipos de 'agravantes'. Probablemente, ante la ausencia en el Derecho criminal romano de una doctrina clara y una construcción lógica [...] han tratado de salir al paso y rellenar lo que considerarían laguna utilizando conceptos actuales, un cuadro de circunstancias agravantes que responden a un Derecho penal actual, pero que no existe en Derecho romano. / Ferrini [...] llega a establecer un cuadro de las principales 'agravantes' que inciden en los distintos delitos [...] Es evidente que no se trata de circunstancias agravantes en el sentido moderno [...]". Por cierto que la ausencia de un cuadro de agravantes (contemporáneas) no implica sin prueba la ausencia de agravantes (en un sentido puro y no técnico contemporáneo): la (im)pertinencia de éstas últimas es lo que hay que constatar conforme al desarrollo y resultado de cada investigación a la hora de (in)admitirlas. Por el contrario, es Montanos Ferrín, ibidem, p. 115, quien parte de un concepto contemporáneo: "Ninguna de las diecisiete agravantes contempladas en el artículo 10 de nuestro Código Penal se puede apreciar en los distintos supuestos delictivos contemplados en las Partidas". 
las sucesivas descripciones del tipo delictivo se apuntan estos elementos, cuya aparición por lo demás corre pareja a la reconsideración del tipo de cara a las nuevas penas que la política criminal arbitra. Esta fragmentariedad y descriptividad del tipo delictivo explica también perfectamente la mutación y cristalización de tipos delictivos con agravantes en nuevos tipos delictivos. Como es obvio, todo lenguaje técnico tiende, cuando adquiere una determinada densidad material, a independizarse conceptualmente. Es lo que sucede con el ejemplo del abigeato, que por cierto no está exento de posibles agravantes ${ }^{22}$. Curiosamente, Montanos Ferrín desplaza la supuesta agravación del delito a la agravación de la pena: si la pena se agrava, el delito es nuevo ${ }^{23}$, y por lo tanto - parece decirse - aquello que la agrava es en puridad, respecto del delito, una razón de su novedad — un elemento constitutivo del tipo ${ }^{24}$ - y no un elemento circunstancial. (Tiene que ser así, y no cabe se trate del mismo delito con pena agravada, porque, si se trata del mismo delito, lo que agrava su pena resultará una circunstancia anexa, puesto que el tipo sustantivamente no ha variado, sigue siendo el mismo, y por lo tanto absurda la exclusión de agravante accidental, contra la propia hipótesis ${ }^{25}$.) Aunque se mantenga esta idea para el Derecho romano-visi-

${ }^{22}$ Desde luego, cuando se afirma el abigeato como ejemplo de delito distinto - y no de un tipo básico agravado - no puede salvarse la circunstancia de que también el abigeato contempla agravantes diciendo -Montanos Ferrín, "La inexistencia", pp. 82-83- que "La situación descrita se refiere solamente a posibles efectos sancionatorios". El propio tipo delictivo distinto que constituye el abigeato germina a efectos sancionatorios. Así, la argumentación comienza a viciarse, como sucede en p. 83 a propósito de una observación de Mommsen: "Por lo que se refiere a la frecuencia en su realización, todavía hay un texto en que este autor aprecia, de nuevo, la existencia de 'reincidencia' como 'agravante'. [...] Alude al hecho de que en aquellos lugares donde el abigeato es más frecuente, se suele castigar a sus autores con más dureza, imponiéndoles incluso la pena de muerte, mientras que en otras partes se les imponen penas menores. No es que la frecuencia en su realización agrave el delito en sí. Lo que se evidencia es la existencia de zonas en que, por una serie de circunstancias, probablemente por ser zonas ganaderas, el robo de ganado que encarna este delito se repite; para evitarlo se extrema la dureza en la aplicación de la pena, lo que no resulta necesario en otras zonas en que no se produce más que de una forma aislada”. En fin, si es una razón punitiva la que explica la inexistencia de agravantes, supongo que esa misma razón punitiva que dio lugar a la aparición del tipo delictivo nuevo disuelve por sí misma la aparente novedad del tipo delictivo. Tropiezas con el absurdo.

${ }^{23}$ Montanos Ferrín, "La inexistencia”, p. 88: "Lo único que se está previendo en todos estos supuestos [de supuestas agravantes] es una agravación de la pena [...]".

${ }^{24}$ Montanos Ferrín, "La inexistencia", p. 93.

${ }^{25}$ A pesar de la tecnificación del lenguaje jurídico, la consideración de la mutación de penas como constitutiva de alteraciones en el tipo delictivo implica un razonamiento contra el sentido común (y el sentido común exige, por así decir, derogación expresa en el lenguaje técnico, una dogmática explícita), porque un mismo delito puede merecer distintas penas según la dureza o piedad de la justicia, y esta dureza o piedad se legitima en una gravedad que lo es del delito, y la gravedad presupone a su vez una qualitas circunstanciada que afecta al tipo delictivo, pero precisamente porque es una qualitas circunstanciada no se entiende como mutación del propio tipo. Ya que la argumentación de Montanos Ferrín se remonta al Derecho romano, permite el humor negro de Apuleyo, El asno de oro (trad. J. de la Vega y Marco), Valencia-Madrid, 1909, libro 6, 31-32: "Mientras devoran con ávida voracidad, empiezan a deliberar acerca de nuestro castigo. Como no podía menos de ocurrir en tan turbulento conciliábulo, las opiniones 
godo, también podría apoyarse a primera vista con la doctrina moderna: el asesinato o el parricidio parecen definirse a partir de la agravación de la pena (¡de muerte!). Si se mira bien, estos casos en los que el tipo delictivo de homicidio se renombra con singularidad forman parte de un catálogo donde el renombramiento no es tan sustantivo - la proditio \& alevosia se manifiesta a menudo, adjetivamente, como homicidio proditorie \& alevose - , puede ser adjetivo — el homicidio praecedente diffidatione, por ejemplo - o asume locuciones verbales — como el suicidio: quando quis seipsum interfecerit; o el envenenamiento: quando quis occidit alium cum veneno- pero siempre en el seno del homicidio. E indudablemente no sólo estas variantes afectan al homicidio en cuanto tipo delictivo: son variantes planteadas en relación con la agravación de la pena. Pero la pena que se agrava - y puede tratarse no tanto de la pena cuanto de su forma de ejecución (así el arrastramiento, en la pena de muerte) es la pena del homicidio, remite al tipo delictivo del homicidio. De manera que esas figuras, terminológicamente sustantivas o adjetivas o verbales, se configuran como una qualitas del homicidio ${ }^{26}$. Una qualitas del delito que conduce por lo tanto a una agravación de la pena, hablando rigurosamente. Y conviene llegar a esta conclusión por el prudente camino trazado antes de decir lo primero que sin embargo a uno le podría haber apetecido: ¿qué visión petrificada y antievolutiva puede tenerse de un sistema jurídico para entender que toda nueva pena da lugar a un delito nuevo? Si cambia la pena de un delito romano-visigodo de nombre persistente, en el seno de su

fueron muy distintas. Pedía uno que la muchacha fuese tostada viva; otro que debía ser despedazada por las fieras; el tercero que la clavasen en cruz, el cuarto que la mutilasen en medio de grandes tormentos; pero todos convenían en que debía morir. Entonces un bandido, después de haber hablado los demás, pronunció gravemente estas palabras: 'No conviene a los principios que nuestra sociedad profesa, ni a la dulzura de carácter de cada uno de nosotros en particular, ni a mi personal moderación, que yo autorice una crueldad que es excesiva y va mas allá que la gravedad del delito. No penséis en las fieras, ni en las aves de rapiña, ni en el fuego, ni en los tormentos; ni os precipitéis tampoco a condenarla a las tinieblas de una temprana muerte. Si atendéis mis consejos, daréis la vida a esta muchacha, pero la vida que merece. No habéis olvidado, sin duda, lo que anteriormente decidimos respecto a este asno, penco gandul y que gasta por cuatro; el mismo que hace un momento fingía una falsa enfermedad, y que ha sido cómplice y agente en la fuga de la niña. Propongo que mañana sea degollado, que le vaciemos completamente las entrañas, encerrar en su pellejo la muchacha, completamente desnuda, coser de nuevo el pellejo de modo que sólo asome la cabeza, quedando aprisionado el restante cuerpo entre los flancos del animal, y que se coloque, finalmente, en lo alto de una roca batida por los ardientes rayos del sol, nuestro asno relleno. De este modo sufrirán los dos el castigo que justamente merecen: el asno alcanzará una muerte que bien ganada tiene, la muchacha aguantará los mordiscos de las fieras, cuando los gusanos consuman sus miembros; los tormentos del fuego cuando el sol, con sus rigorosos ardores, inflamará la piel del animal, y finalmente el suplicio de las aves, cuando los buitres rasgarán sus entrañas. Imaginad, además, los tormentos suplementarios de que disfrutará. Viva todavía vivirá en el pellejo de un asno muerto, sofocando su olfato el más fétido olor, se irá aniquilando con el martirio del hambre, y ni aun podrá disponer de sus manos para darse la muerte.' Cuando hubo terminado, todos, sin necesidad de votación, estuvieron conformes con esta proposición, con unánime asentimiento. Y yo, que todo lo había oído con mis largas orejas, iqué otra cosa podía hacer, sino llorar por mi desdichado cuerpo, mañana cadáver!".

${ }^{26}$ Antonio Gómez, Variae, III, 100-106. 
evolución, ¿también tenemos un delito nuevo, o sea, delitos homónimos? Por otra parte, ¿el número de cabras, puercos u ovejas es irrelevante y no hace nacer un clon del abigeato, mientras que una pena del cuádruple o del undécuplo da lugar a distintos delitos de robo ${ }^{27}$ ? En fin, Alfonso de Azevedo sentencia: gravitas enim ex insidiis procedens aggravat delictum \& poenam ${ }^{28}$; de manera que la gravedad se aplica al delito a través de la qualitas, o se aplica simultáneamente al delito y a la pena, estabilizado el noema. El hecho de que, a tenor del análisis ejecutado supra, la subsidiariedad afecte al tipo de pena, se comprende así, nunca como criterio expresivo de que no pueda agravarse exclusivamente la pena (sería descabellado), sino como un refuerzo más de que esa agravación de la pena no implica por necesidad un trastorno del tipo delictivo, en tanto que una agravación del tipo delictivo deriva en una agravación de la pena, es decir, la agravación del tipo delictivo se precipita hacia una agravación completa (delictum \& poena) del tipo completo delictivo-penal.

Pedro Ortego Gil ha escrito páginas sobre este asunto que me parecen intachables, aunque no comprendo que su planteamiento se califique en equilibrio aunque más próximo a la postura tradicional - aceptación de agravantes - frente a la de Montanos Ferrín. Las citas de Gregorio López, Alfonso de Castro y Jerónimo Castillo de Bovadilla acerca de las circunstantiae delicti son muy esclarecedoras ${ }^{29}$. Pero la perspicacia del planteamiento de Ortego Gil tiene que ver, sobre todo, con la localización del problema en el estudio de la relación entre dos términos, circunstantiae delicti y qualitas, hacia la que también aquí se ha derivado finalmente. Y sus páginas ponen explícitamente de manifiesto la comunión y proximidad semántica entre aquellos términos, así como, más implícitamente, la preparación de la dogmática y paulatina acomodación sistémica — conforme se compartimenten otros factores técnicos: capacidad, imputabilidad y culpabilidad, etc.- de unas ya definidas circunstancias modificativas de la responsabilidad criminal en el esquema penal contemporáneo ${ }^{30}$. Al concretar el uso histórico de las circunstancias y cualidad, Ortego Gil hace lo que se espera del historiador: dar las claves de la pertinencia ${ }^{31}$. Podrá disertarse entonces

\footnotetext{
${ }^{27}$ Cf. Montanos Ferrín, "La inexistencia”, pp. 82, 100, que no plantea ni resuelve el problema de la homonimia en el lenguaje jurídico, al que da lugar su reflexión.

${ }^{28}$ Alfonso de Azevedo, Commentarii juris civilis in Hispaniae regias constitutiones. Tomus quintus, octavum librum novae recopilationis complectens, Lugduni, apud fratres Deville, 1737, p. 438.

${ }^{29}$ Pedro Ortego Gil, "El fiscal de Su Majestad pide se supla a mayores penas. Defensa de la justicia y arbitrio judicial”, Initium. Revista Catalana d'Història del Dret, 5, 2000, pp. 322-328.

${ }^{30}$ Ortego Gil, "El fiscal de Su Majestad", pp. 329-340. Todas estas páginas son de lectura obligada para el problema en lid, pero valgan las siguientes palabras-preámbulo: "Tanto en la legislación como en la literatura jurídica castellana se emplea de forma habitual y general el sustantivo de cualidades junto con el de circunstancias [...]" (p. 329); más adelante: "Al concluir el siglo XVIII los juristas separan con nitidez las que ellos consideran circunstancias del delito y las circunstancias de la pena" (p. 337).

${ }^{31}$ La conexión, por mor de la pertinencia, entre circunstancias modificativas de la responsabilidad criminal y circunstantiae delicti o qualitas, se observa perfectamente en la estructura del trabajo de Enrique Gacto Fernández, "Las circunstancias atenuantes de la responsabilidad criminal en la doctrina jurídica de la Inquisición”, en E. Gacto Fernández, Estudios jurídicos sobre la Inquisición española, Madrid,
} 
acerca de las circunstancias agravantes no porque las agravantes sobre las que se diserta por parte del historiador sean las agravantes sobre las que diserta la fuente, sino en cuanto sea pertinente el uso significativo de las primeras respecto del uso significativo de las segundas. Sinceramente, no creas que ningún historiador de los citados por Montanos Ferrín intente trasladar una clasificación cerrada contemporánea, ni que resulte impertinente en el uso del término agravante, sin perjuicio de que puedan discutirse errores (de los que nadie está a salvo) en el respeto de la pertinencia. A su vez estos errores de pertinencia hay que vaticinarlos tanto más improbables justamente por la amplitud de las circunstantiae y de la qualitas en el uso histórico concreto, precisamente en la medida en la que el sistema jurídico-criminal se construye desde la descriptividad del tipo delictivo y de su fragmentariedad, inductivamente, y no desde una arquitectura dogmática predeterminada de elementos constitutivos y accidentales del delito.

Por otra parte, en una teoría como la de la inexistencia de circunstancias modificativas de la responsabilidad criminal en el Derecho histórico late una crítica hacia una concepción de la Historia jurídica en un sentido textual, como si la sedimentación de la evolución de las instituciones en las fuentes provocara una disecación lingüística en el sentido no tanto de impedir la detección de mutaciones semánticas en la terminología y en los conceptos, armonías y discordias entre voces propiamente de las fuentes y voces del historiador explicativas de las fuentes, sino en la línea, más profunda, de impedir la comprensión de esos términos, conceptos y voces como resultado de una vida que los hace aflorar y finalmente los arroja en los textos, determinados y condicionados por una génesis. La lectura sería por lo tanto un acto estático que entrañaría el riesgo de impedir el entendimiento de que los significados han sido alumbrados en una dinámica real, y que esa dinámica, vital y también lingüística, ha de ser atendida a la hora de comprender el significado con el que caen en los textos. En este sentido habría de batallarse también contra la anacronía. Esto recuerda aquella reflexión de Henri Bergson cuestionando la virtualidad del intelecto a la hora de comprender la realidad, a propósito de la natación. Decía Bergson que el hombre que no

2012, pp. 101-143, que por tratar de atenuantes recoge además la terminología rigurosa que concreta aquéllas en el término de defensio: "He partido en este trabajo del concepto de circunstancias atenuantes en el sentido que los tratadistas del Derecho penal inquisitorial dieron al término defensiones: elementos accidentales del delito que inclinan al juez a la imposición de una pena inferior a la que estaba prevista en el ordenamiento jurídico para sancionar el delito de herejía o cualquiera de los delitos menores sobre los que la Inquisición tenía reconocida competencia" (p. 101). Las circunstantiae presentes en la qualitas que agrava y en la defensio que atenúa son el contenido estricto y pertinente de las (así dichas) agravantes y atenuantes. A saber, en el caso de las atenuantes tal y como las contempla Gacto: circunstancias referidas al delicuente (subjetivas - ignorancia, locura, ira, edad, sexo...-, objetivas - miedo y violencia, estado de necesidad...- y mixtas — reiteración, arrepentimiento...-), circunstancias referidas al delito (parvedad de materia, resultado menor del pretendido) y circunstancias metajurídicas de política criminal (edicto de gracia, multiplicidad de delincuentes, condición eclesiástica del delincuente). Por supuesto, éste es un claro ejemplo de cómo la pertinencia anula cualquier riesgo (y crítica) de anacronía. 
sabe nadar, para aprender a hacerlo, pensará que debe lanzarse al agua y flotar, aunque quedará perplejo al darse cuenta de que, para flotar y no hundirse, cabalmente tiene que saber nadar, de modo que su inteligencia tiende a bloquearse en un círculo vicioso que le impide el aprendizaje. El intelecto no es útil. Para aprender a nadar, tiene que lanzarse al agua sin tanto razonamiento, y será la vida en el agua la que encontrará la forma del aprendizaje que el intelecto no alcanzaba ${ }^{32}$. Pues bien, la catalogación intelectual de los contenidos de las fuentes no sería suficiente para comprender su significado - por eso, podría decirse, hay tanta aparente comunión de problemas que, por responder a tiempos diferentes, deberían preconcebirse como distintos (sin que sirva la excusa de la persistencia problemática de lo humano) - sino que se requiere la percepción de su natación real y circunstanciada, en la que se aloja su singularidad. Quien considera agravantes aquellas circunstancias que un sistema jurídico no cataloga como tales está leyendo la fuente sin comprender la vida de sus conceptos, la forma en la que la vida arroja los conceptos a los textos y cuaja la sintaxis.

Ahora bien, si se piensa en el Derecho moderno y en la persistencia que en él tiene el Derecho bajomedieval, el momento en el que la vida arroja los tipos delictivos a los textos (me permito decirlo así, aunque los tipos nazcan una vez son arrojados) tiene que ser anterior. Tiene que ser anterior, entiéndase, si lo que se pretende es la búsqueda del momento genesíaco de la formación del tipo. Por eso hay que acudir al Derecho altomedieval, en este problema ${ }^{33}$. Pero a su vez el momento, aun previo, no debe ser un momento lejano, porque el Derecho persistente debe explicarse en su génesis conceptual nunca en virtud de un sistema radicalmente extraño o temporalmente alejado. Al menos se concederá - aunque se otorgue mayor valor a la influencia conceptual del Derecho romano-canónico en el Derecho bajomedieval y moderno- que esta influencia debe comulgar con la de la tradición más cercana, menos alejada. De nuevo hay que decir que tiene sentido entonces la lectura del Derecho altomedieval, pero sobre todo porque su lenguaje no es tan altomedieval como parece. Es decir, los fueros locales comienzan a tomar un brío conceptual suficientemente propio, al menos en materia penal, sólo en el siglo XII; esto aproxima su lectura, y la hace más pertinente, respecto de las fuentes consideradas plenamente bajomedievales. Y lo que demuestra el análisis de los tipos delictivos en los fueros del siglo XII es sin duda el nacimiento fragmentado y puramente descriptivo de los tipos delictivos ${ }^{34}$, trufados de circunstancias subjetivas y objetivas, y con variedad de penas, hasta tal punto, que si toda especie fuera género, no existiría género, y consiguientemente tampoco ninguna especie, sólo habría $\varnothing$, pura nada. En consecuencia, lo que la vida arroja a los textos es un aluvión de tipos delictivos — armas vetadas, heridas, bandos, muertes,

\footnotetext{
${ }^{32}$ Henri Bergson, La evolución creadora (trad. J. A. Míguez), Madrid, 1963, pp. 604-606.

${ }^{33}$ Y así lo hace efectivamente Montanos Ferrín, "La inexistencia”, pp. 101-110, para seguir defendiendo la inexistencia de circunstancias agravantes en los fueros.

${ }^{34}$ Remito a mi trabajo "Reseña de males y penas en fueros y costumbres del siglo XII", Initium. Revista Catalana d'Història del Dret, 18, 2013, pp. 385-451.
} 
falsedades, etc.- cuya relevancia delictiva brota de su descripción, y cuyas variables son continuamente matizadas por las circunstancias. Y si bien ese lenguaje no cataloga ni los males como delitos, ni las circunstancias como agravantes, una lectura histórica en estos términos no tiene por qué ser excluida como pertinente si parte del dato esencial, del dato fundamental, del presupuesto que asimismo otorga pertinencia al discurso inmediato bajomedieval y moderno: la descriptividad y la fragmentación como forma de alumbrar y expresar los tipos delictivos ${ }^{35}$, frente a una presupuesta unicidad del tipo que, al no encontrarse explícita (porque no existe), prefiere ser salvada a riesgo de una multiplicación de tipos delictivos contra el sentido común de su propia comunidad y sintonía vital. La vida en definitiva demuestra que el historiador no puede ser impertinente, mas también que, si demuestra ser pertinente, hay lenguas distintas para expresar una misma realidad, una realidad que se fue y ya no puede ser

${ }^{35} \mathrm{Y}$ esta descriptividad y fragmentariedad no excluye, como es natural, un afán expositivo ordenado, de la literatura jurídica moderna, en el que influye la mirada y reflexión de cada autor. A su vez, no puede comprenderse a estos autores si se excluye la idea de una tipicidad delictiva descriptiva y fragmentada. A propósito de Antonio Gómez, referencia de estas páginas sin ningún empacho, dice Montanos Ferrín, "La inexistencia", p. 127: "Llama la atención que algunos de estos autores hacen caso omiso de la tradición jurídica y desvirtúan el concepto de los diferentes delitos. En este sentido, Antonio Gómez, en sede de homicidio, se pregunta 'in quibus casibus istud delictum homicidii, eius poena aggravetur', y de forma sorprendente, da cuenta de seis situaciones en las que, según define, aparece como 'agravado' el delito de homicidio. Estos 'casos' son: la muerte del padre, madre o ascendiente, el matar con traición o alevosía, el matar con veneno, el dar muerte a una persona a instancia de alguien mediante precio, el matar tras un acuerdo entre varios y, por último, el darse muerte a sí mismo. En verdad, sorprende que Antonio Gómez vea en estas situaciones sólo un homicidio que merece una agravación de la pena por las especiales características que reviste. Cada uno de los supuestos mencionados por Antonio Gómez son ni más ni menos que los viejos y conocidísimos tipos de parricidio, asesinato, envenenamiento y otra sorpresa - el suicidio. No se comprende en tan celebrado tratadista". La tradición que no sigue Antonio Gómez no es la tradición jurídica, sino la tradición de Montanos Ferrín, y los "viejos y conocidísimos tipos" son citados por Antonio Gómez, por supuesto, expresamente, con su terminología propia, sin perjuicio de su propio planteamiento; a Antonio Gómez, en fin, se le entiende perfectamente (y la mención del suicidio no causa ninguna sorpresa) por mucho que no coincida con la lectura de las fuentes que hace Montanos Ferrín. A continuación, en la misma página, la historiadora añade: "Mateo y Sanz, considerado por algunos como el más destacado práctico, incide en el mismo error de Antonio Gómez y, de esta manera, dispone que, en el supuesto de dar muerte a una persona, 'tria specialia aggravantia concurrerent'. Estas tres especies agravadas son, según este autor, el parricidio, el matar por precio y el matar con armas. Y la consecuencia de su afirmación es, en este autor, la misma: la agravación de la pena con relación al homicidio simple". De manera que Antonio Gómez y Lorenzo Matheu y Sanz no conocen las bases conceptuales mínimas del Derecho de su época, ni teórica ni prácticamente. Sin duda, es apabullante y pasmosa y asombrosa una conclusión así. Hay que reconocerle a Montanos Ferrín que no se arredre y arrase con las opiniones que no se adaptan a su prejuicio, cual panzer. Pero, ¿dónde ha quedado entonces la preocupación por la anacronía? ¿Son anacrónicos los crónicos, o más bien anacrónica la crónica? Queda invitado el lector a aplicar las distintas posturas sobre la cuestión juzgada al trabajo de Emma Montanos Ferrín, "Cum obscurabatur", Anuario da Facultade de Dereito, 2 (1998), pp. 351-368, que a la sazón apuntaba esta línea de sombra en "An de die vel de nocte", en Rivista Internazionale di Diritto Comune, 9 (1998), pp. 49-80, donde recuerda y defiende su teoría, aquí en la picota, con pertinacia, si no con pertinencia. 
expresada con la boca, los gestos, el estilo de los muertos, como ya nadie puede escuchar a Horacio con los oídos de Mecenas, pero que puede ser traducida y entendida. Sería extraño, además, que un sistema incapaz de construir una agravante como elemento accidental, fuera capaz de la abstracción violenta de entender como tipos distintos un hurto diurno y un hurto nocturno, o sea de darse cuenta, antes que de si es de día o es de noche, de las separadas cajas de hurtos, en eso que el común de los mortales llama hurto, hurto aquí o hurto allá, hurto una y otra vez, hurto propio o hurto impropio, llueva o nieve o salga el sol por Antequera. 